Counselor preparation for working with at-risk youth

By: Jonathan H. Ohrt, Brooke C. Wymer, Jessie D. Guest, Dodie Limberg, Ryan G. Carlson, and Jennifer Deaton

Ohrt, J., Wymer, B., Guest, J., Limberg, D., Carlson, R., \& Deaton, J. D., (2019). Counselor preparation for working with at-risk youth. Journal of Child and Adolescent Counseling, 5(2), 113-129. https://doi.org/10.1080/23727810.2019.1586417

This an Accepted Manuscript of an article published by Taylor \& Francis in Journal of Child and Adolescent Counseling on 2019 June 13, available online: http://www.tandfonline.com/10.1080/23727810.2019.1586417

It is deposited under the terms of the Creative Commons Attribution-NonCommercial License (http://creativecommons.org/licenses/by-nc/4.0/), which permits non-commercial re-use, distribution, and reproduction in any medium, provided the original work is properly cited.

\begin{abstract}
:
In this article, we provide an overview and evaluation of a federally funded training program designed to increase access to mental health services for at-risk children, adolescents, and transitional-age youth by expanding the number of behavioral health providers trained to provide evidence-based services. We present evaluation data and implications for counselor education and supervision.
\end{abstract}

Keywords: at-risk populations | interdisciplinary collaboration | program evaluation | counselor training

\title{
Article:
}

Mental health concerns are common among children and adolescents nationwide. As cited in Stegman and Cooper (2010), the National Center for Children in Poverty (NCCP) reported that 1 in 5 children from birth to age 18 has a diagnosable mental disorder, and 1 in 10 youth has a serious mental health problem that impacts functionality at home, in school, or in the community. In addition, according to the results of the 2017 National Survey on Drug Use and Health administered by the Substance Abuse and Mental Health Services Administration (SAMHSA), 24\% of youth ages 12 to 17 had engaged in illicit drug use in their lifetimes, and $58 \%$ of youth in this age range had engaged in alcohol use during the past month. The onset of major mental illness may occur as early as 7 to 11 years old, and roughly half of all lifetime mental health disorders start by the midteens (Stegman \& Cooper, 2010). Children and youth are at increased risk for mental health problems when living in low-income households, having unemployed or teenage parents, or being in the foster care system, among other risk factors. Moreover, 21\% of low-income children and youth ages 6 to 17 have mental health problems, and $57 \%$ of these children and youth with mental health problems come from households living at or below the federal poverty level (Stegman \& Cooper, 2010). When young adults age, peer 
influences remain strong, while family and parental influences dissipate due to less parental supervision and more independence (Cleveland, Feinberg, Bontempo, \& Greenberg, 2008; Ellickson, Orlando, Tucker, \& Klein, 2004; Hadiwijaya, Klimstra, Vermunt, Branje, \& Meeus, 2017; Sessa, 2005; Tang \& Orwin, 2009; Wechsler \& Nelson, 2008). Thus, familial, peer, and environmental factors greatly influence the mental health of children, adolescents, and young adults.

Children and youth with mental health problems also struggle to succeed academically (Larson, Chapman, Spetz, \& Brindis, 2017; McLeod \& Fettes, 2007). For example, children and youth with mental health issues are likely to experience rates of absences or suspensions three times higher than those of their peers and display lower educational achievement compared to children with other types of behavioral issues (Stegman \& Cooper, 2010). Further, children and youth with mental health disorders and significant environmental stressors are also more likely to fail or drop out of school (Deighton et al., 2018; Dupéré et al., 2018; McLeod \& Kaiser, 2004; Needham, Crosnoe, \& Muller, 2004; Needham et al., 2004; Vitaro, Brendgen, Larose, \& Tremblay, 2005). Mental health disorders are widespread and can contribute to lasting family, social, academic, and career maladjustment.

Despite the documented need for mental health services among youth, most do not receive the needed services. In fact, it is estimated that less than half of youth who have mental health concerns receive any services at all (Merikangas et al., 2010). The U.S. Health Resources Services Administration (HRSA) recognizes the need for greater access to mental health services and has allocated funding to training programs to increase the behavioral health workforce. In this article, we describe the structure of a one-year, federally funded training program that was implemented at a large public university in the Southeast. Furthermore, we discuss findings from qualitative evaluations of the program.

\section{PROGRAM STRUCTURE}

At the time of the project, the counselor education program included entry-level degree tracks in school counseling and marriage, couples, and family counseling. Both degree programs are accredited by the Council for the Accreditation of Counseling and Related Educational Programs (CACREP) and consist of 66 graduate credit hours. This project was implemented as part of the Behavioral Health Workforce Education and Training (BHWET) program supported by HRSA and SAMHSA. The overall goal of the BHWET program is to increase access to mental health services for at-risk children, adolescents, and transitional-age youth by expanding the number of behavioral health providers (e.g., counselors) who are competently trained to work with these populations. The BHWET program defines "at risk" as individuals who have a higher risk than others of developing substance use or mental health problems due to an interaction of environmental, biological, and behavioral factors and may include individuals from low-income families or medically underserved communities. In addition to expanding the behavioral health provider workforce, we addressed the following aims in our project: (a) expand internship site placements for our students to gain experience working with at-risk youth, (b) provide opportunities for interdisciplinary collaboration, and (c) increase students' knowledge and ability to implement evidence-supported practices with at-risk children, adolescents, and transitionalage youth. A detailed description of the project is provided in the sections that follow. 


\section{Site Placements}

Program faculty utilized existing partnerships and developed new partnerships for internship site placements for students. Internship students committed to working with at-risk children, adolescents, transitional-age youth, or families at their placements. In addition, to qualify as an appropriate placement, internship sites had to provide opportunities for students to engage in interdisciplinary collaboration. In total, 20 students completed internships at 18 sites, which included $\mathrm{K}-12$ educational settings, community mental health organizations, and state social service agencies. A summary of placements and populations is included in Table 1.

Table 1. Participant Action Research Projects

\begin{tabular}{|c|c|c|}
\hline Population & Setting & Intervention Focus \\
\hline $\begin{array}{l}\text { Adolescent females with substance } \\
\text { abuse history }\end{array}$ & High school & Emotional health group \\
\hline Adolescent males in danger of failing & High school & $\begin{array}{l}\text { Cultural identity development and goal-setting } \\
\text { group }\end{array}$ \\
\hline $\begin{array}{l}\text { Adolescents with expulsion hearings } \\
\text { pending }\end{array}$ & High school & $\begin{array}{l}\text { Individual cognitive behavioral therapy focused } \\
\text { on self-esteem and self-efficacy }\end{array}$ \\
\hline $\begin{array}{l}\text { Adolescents failing } 9 \text { th grade for the } \\
\text { second time }\end{array}$ & High school & Career- and goal-focused group \\
\hline $\begin{array}{l}\text { 9th grade students transferring in as } \\
\text { new students }\end{array}$ & High school & School membership-building group \\
\hline Adolescent males & Middle school & Leadership development group \\
\hline $\begin{array}{l}\text { Children ages } 6 \text { to } 12 \text { years, } \\
\text { adolescents ages } 15 \text { to } 19 \text { years }\end{array}$ & $\begin{array}{l}\text { Mental health treatment } \\
\text { clinic }\end{array}$ & $\begin{array}{l}\text { Individual cognitive behavioral therapy focused } \\
\text { on self-worth and resiliency }\end{array}$ \\
\hline $\begin{array}{l}\text { 1st grade classes with difficulty } \\
\text { transitioning }\end{array}$ & Elementary school & $\begin{array}{l}\text { Classroom guidance intervention to build learning } \\
\text { skill development }\end{array}$ \\
\hline $\begin{array}{l}\text { Adolescents with expulsion hearings } \\
\text { pending }\end{array}$ & Family therapy clinic & $\begin{array}{l}\text { Individual CBT to promote self-regulation and } \\
\text { resiliency }\end{array}$ \\
\hline $\begin{array}{l}\text { Adolescents referred for behavioral } \\
\text { intervention }\end{array}$ & Middle school & Pro-social coping skill-building group \\
\hline $\begin{array}{l}\text { Elementary-aged females with } \\
\text { minority status }\end{array}$ & Elementary school & Self-esteem and social skills-building group \\
\hline $\begin{array}{l}\text { Elementary-aged females with peer } \\
\text { aggression }\end{array}$ & Elementary school & Social and emotional learning group \\
\hline Children & Elementary school & Academic success group \\
\hline $\begin{array}{l}\text { College-aged youth with overall } \\
\text { distress }\end{array}$ & University & Integrated individual therapy approach \\
\hline $\begin{array}{l}5 \text { th grade females with behavioral } \\
\text { referrals }\end{array}$ & Elementary school & Resiliency group \\
\hline $\begin{array}{l}\text { Elementary-aged children with } \\
\text { anxiety symptoms }\end{array}$ & Elementary school & Pro-social coping skills-building group \\
\hline $\begin{array}{l}\text { Adolescents in danger of not } \\
\text { graduating }\end{array}$ & $\begin{array}{l}\text { High school career } \\
\text { center }\end{array}$ & $\begin{array}{l}\text { Increasing self-efficacy in a social cognitive career } \\
\text { theory group }\end{array}$ \\
\hline $\begin{array}{l}\text { Transitional-aged youth with visual } \\
\text { disabilities }\end{array}$ & $\begin{array}{l}\text { State social service } \\
\text { agency }\end{array}$ & Trauma-informed individual therapy \\
\hline
\end{tabular}

\section{Interdisciplinary Collaboration}

At-risk children, adolescents, transitional-age youth, and their families often receive support from multiple social service professionals to address clients' needs within educational and social 
service institutions. Consequently, counselors must adapt to the changing needs of clients by engaging in collaboration with the service providers involved with clients in a variety of organization and educational settings. Moreover, the Patient Protection and Affordable Care Act (2010) requires behavioral health providers to participate in interdisciplinary teams within medical settings to identify individuals in need of mental health care and ensure access to mental health services for those who need them (Cox, Adams, \& Loughran, 2014). School counselors are also required to engage in collaborative efforts with school personnel and other community resources to promote overall wellness and foster students' academic achievement (American School Counselor Association [ASCA], 2016). In addition, mental health counselor training programs have started to implement educational interventions for mental health providers in training to promote interprofessional collaboration competency in students interning in school settings due to this skill being vital to meeting youths' needs (Iachini et al., 2015; Splett, Coleman, Maras, Gibson, \& Ball, 2010).

Given the importance of promoting students' competence for interdisciplinary collaboration, we targeted site placements that included opportunities for counselors to collaborate with other disciplines when providing services. This process also included targeting placements that provided some level of behavioral health integration with primary care. The counseling program faculty conducted a training on interdisciplinary collaboration prior to students' starting their site placement. The training included definitions, competencies (Interprofessional Education Collaborative Expert Panel, 2011), and case examples. We also hosted a workshop on behavioral health integration in primary care. The presenter was a local agency director who has more than 15 years of experience with primary care integration. Finally, the professional development opportunities provided in this program (discussed further in the following section) consisted of interdisciplinary approaches to working with at-risk populations.

\section{Knowledge and Implementation of Evidence-Based Practices}

To support students' knowledge acquisition related to evidence-based practices, we hosted a workshop and provided full funding for students to attend two conferences that included sessions focused on interdisciplinary approaches to working with at-risk populations. All of the students who participated in this project attended all training opportunities. Faculty in the counselor education program organized and hosted one of the conferences at the university. The theme of the conference was "Strategies forWorking with At-Risk Children, Adolescents, TransitionalAge Youth, and Families." Session topics included strategies for working with a variety of populations considered at risk. Presenters represented various disciplines, such as psychology, psychiatry, special education, marriage and family therapy, clinical mental health counseling, and school counseling. Students also attended the Southeastern School Behavioral Health Conference, which included presentations focused around five themes: (a) improving collaboration among families, educators, clinicians, and other youth-system staff, (b) schoolwide approaches for prevention and intervention, (c) improving quality of services, (d) increasing implementation support, and (e) enhancing cultural humility and reducing racial, ethnic, and other disparities. The purpose of the professional development opportunities was to improve students' working knowledge of evidence-based practices and implementation processes. 
As part of the implementation process, students engaged in action research at their site placement. Prior to the internship, program faculty conducted a presentation on appropriate procedures for conducting action research, including (a) identifying clients, (b) implementing appropriate interventions, and (c) collecting data and interpreting results. The purpose was for students to utilize the knowledge they gained from the trainings and conferences in practice, while also evaluating their effectiveness and demonstrating practice-based evidence of their clinical interventions (Brott, 2006). Students also presented their results in a poster format at a program-sponsored symposium. During the presentation, students (a) described the characteristics of their clients and explained why they were at risk, (b) outlined the evidencedbased prevention or treatment intervention used with the clients, (c) described the assessments used to track client progress, and (d) analyzed client data and interpreted outcomes of the intervention. Descriptions of the students' action research projects are outlined in Table 1, which includes the internship setting, populations receiving services, and type of interventions employed during their action-research experiences.

Several of the students worked with at-risk populations in a high school setting. Some examples of interventions completed in this setting include (a) emotional health groups, (b) leadership and career development groups, (c) cultural identity development groups, and (d) individual and group therapy to increase student self-efficacy. For students working in elementary and middle school settings with at-risk populations, they completed interventions focused on (a) resiliency, (b) self-esteem building, (c) social and emotional learning, and (d) academic success. Other students worked in a variety of mental health settings and completed such interventions as (a) individual cognitive behavioral therapy (CBT) focused on self-worth, self-regulation, and/or resiliency with children and adolescents, (b) integrative care approaches to individual therapy among college-age youth experiencing overall distress, and (c) trauma-focused therapy with transitional-age youth who have visual impairments.

\section{METHOD}

\section{Design}

We did not design the program as a research study; however, we used thematic analysis of focusgroup interviews to evaluate the training program. Thematic analysis is a flexible qualitative approach because it is unbounded by theoretical tenets and can be applied to a range of theoretical frameworks and research paradigms (Clarke \& Braun, 2016). We also included a posttraining evaluative questionnaire to collect supplemental descriptive information about program efficacy.

\section{Grant Evaluation Team}

The grant evaluation team consisted of two White male counselor education faculty members, one White female faculty member, and three White female counselor education doctoral students who are affiliated with the same Southeastern counselor education program. The lead researchers have several years of counseling experience and as counselor educators working with the identified population. The three doctoral students have clinical backgrounds working with the 
targeted populations in this program. Each of us is highly invested in promoting effective services for at-risk populations.

Participants

All 20 second-year counselor education internship students who were currently enrolled in the counselor education program were invited and agreed to voluntarily participate in the training program. The participants consisted of two females who identified as more than one race, two males who identify as Black/African American, two women who identify as Black/African American, and three men who identify as Caucasian/White. The remaining 11 students identified as women and Caucasian/White. Eight of the participants were in the marriage, couples, and family track and 12 of the participants were in the school counseling track.

\section{Data Collection Procedures}

After institutional review board (IRB) approval and completion of the participants' internship experiences working with at-risk children and adolescents, the 20 student participants voluntarily participated in one of two focus groups. Both focus groups were similar in number and demographic makeup, ensuring that each focus group included between 8 and 12 participants (Stewart \& Shamdasani, 1990). Each semistructured focus group lasted 1.5 hours and included two interviewers. We asked three primary interview questions:

1. Tell us about your experiences working with at-risk children, adolescents, transitionalage youth, and their families in your internship setting.

2. Tell us about your experiences receiving training in evidence-based practices and interdisciplinary collaboration.

3. Tell us about your experiences engaging in an action research project in your internship setting.

We recorded the focus groups and transcribed them for data analysis (Stewart \& Shamdasani, 1990).

Table 2. Evaluation Survey Results

\begin{tabular}{|c|c|c|c|}
\hline Prompt & $\begin{array}{c}\text { Disagree } \\
n\end{array}$ & Agree $n$ & $\begin{array}{l}\text { Strongly } \\
\text { Agree } n\end{array}$ \\
\hline I am more confident in my ability to counsel at-risk populations. & & 10 & 10 \\
\hline $\begin{array}{l}\text { I am more knowledgeable about effective interventions to implement with at-risk } \\
\text { populations. }\end{array}$ & & 9 & 11 \\
\hline $\begin{array}{l}\text { I am more confident in my ability to evaluate my effectiveness with clients/students (e.g., } \\
\text { conduct action research). }\end{array}$ & & 5 & 15 \\
\hline $\begin{array}{l}\text { I am more confident in my ability to work with an interdisciplinary team to assist } \\
\text { clients/students. }\end{array}$ & & 4 & 16 \\
\hline I am more knowledgeable about the integration of behavioral health in primary care. & 1 & 8 & 11 \\
\hline $\begin{array}{l}\text { All of the training I received as a part of the grant is something I can implement in my } \\
\text { future counseling profession. }\end{array}$ & & 10 & 10 \\
\hline I plan to work with at-risk populations in my future counseling profession. & & 7 & 13 \\
\hline
\end{tabular}

Note. $N=20$. "Strongly Disagree" is not included in Table 2 because there were no "Strongly Disagree" answers to any of the prompts by any of the participants; however, it was an option provided for response within the evaluation survey. 
After focus-group completion, participants completed a brief online evaluation questionnaire via SurveyMonkey to help support program findings and efficacy. The evaluation consisted of Likert scale questions to gather additional descriptive information regarding the participants' feelings of confidence working with at-risk populations, as well as participants' perceptions of the training received in evidence-based interventions and interdisciplinary collaboration. Evaluation questions and responses are included in Table 2 . All 20 participants responded to the evaluation questionnaire.

\section{Data analysis}

We used thematic analysis to identify, analyze, and interpret themes found within the transcribed data from focus groups (Clarke \& Braun, 2016). We used inductive thematic data analysis to allow the data to drive the coding rather than attempting to fit it into a preexiting framework. We followed the six phases of thematic analysis outlined by Braun and Clarke (2006): (a) researcher familiarization with the data, (b) generation of preliminary codes, (c) exploration of themes, (d) review of themes, (e) identify themes by defining and naming them, (f) and production of a report. Our team met weekly to ensure each phase of the analysis was completed thoroughly prior to moving to the next step. Four of the authors coded the focus groups and two of the authors served as internal auditors.

\section{Trustworthiness}

We addressed four key components to ensure the rigor of the study: (a) credibility, (b) transferability, (c) dependability, and (d) confirmability (Lincoln \& Guba, 1986). To ensure that the information gathered was accurate and credible, we chose a focus-group design to allow for multiple perspectives to be heard and to establish consistency. We addressed transferability by providing in-depth descriptions or direct quotes of the participants' experiences within the document illustrating the ability for this information to be applicable to other settings working with the same or similar populations. Two external auditors who were not a part of the data collection or analysis process reviewed the findings and supported the dependability of the analysis. We addressed data confirmability in two key ways. First, utilizing the inductive approach of thematic analysis focuses on the participants' experiences and responses to direct our coding as opposed to attempting to fit their responses into preestablished frameworks. Second, our research team varies in clinical and professional experiences, which provides different perspectives on the topic. Finally, our evaluation team met weekly and created an open and trusting environment to identify and discuss possible biases as needed.

\section{FINDINGS}

We identified four main themes through thematic data analysis: (a) interdisciplinary collaboration, (b) barriers and challenges, (c) support, and (d) counselor development. In the following section, we describe each theme and related subthemes that provide a more in-depth depiction of the participants' experiences. We provide quotations from the focus groups to augment understanding of themes and subthemes. 


\section{Theme 1: Interdisciplinary Collaboration}

Focus-group participants described the importance of collaboration within and outside their site placements. Participants reported that they were better able to meet the needs of their clients by obtaining and providing feedback within interdisciplinary teams at their organizations, as well as collaborating with other professionals when helping their clients gain needed resources. One participant stated, "It just helped to get different perspectives on things." Another participant reported, "Seeing the importance of how we were collaborating with other people, and that those people got the greatest results, so it helped to support the whole idea that integrative and collaborative care." In addition, the participants described the importance of collaborating with professionals from a variety of disciplines outside of their agencies to give and receive information to produce better results for the at-risk populations they were serving. One participant provided an account of this experience:

"I'm also reaching out to stakeholders and really trying to push for these proper supports. So I guess just basically getting that collaborative, that big picture, because you can't just operate on one level to really make it work."

Two subthemes that emerged in the data included the internal sources of collaboration within the participants' training organization and external sources of interdisciplinary collaboration outside of the participants' training organizations.

\section{Internal}

Students described the feedback and connection to helpful resources they received when participating in interdisciplinary teams within their organizations. One participant stated that the clinical teams within the organization from the previous semester provided different evidencebased articles that the students could use to "help guide what we were doing, so that was very helpful." In addition, students reported that there were times they needed to collaborate with different professionals to help their clients gain necessary resources to meet basic needs before their counseling interventions would be successful. One participant described this experience:

I made really good friends with the social work intern at the school because a lot of my kids ... weren't getting enough to eat at home and things like that. And just thinking, "How am I supposed to work on like trauma, how am I supposed to help you process some of the things that you're going through, if you don't even have your basic needs met?" So that's how I learned to work collaboratively with other professionals at the school.

\section{External}

The participants also reported that they had to provide and gain information from professionals from varying disciplines outside of their training organizations to better serve at-risk children, adolescents, youth, and families. One participant said, "I've actually got to go put together a presentation that I am going to go present to the board in [a neighboring city] because there aren't proper supports in place for these kids." Other students stated that they attempted to 
collaborate with external agencies and professionals to provide a continuum of care; however, the students also noted that collaboration with agencies or organizations outside of their current setting was not always successful. A participant reported,

"But then the frustrating parts are when like you're trying to get in touch with the teacher, or you are trying to get in touch with the social worker and case manager, and they are just not returning your calls."

\section{Theme 2: Barriers and Challenges}

Throughout the data, participants reported experiencing barriers and challenges when counseling at-risk children, adolescents, transitional-age youth, and their families. Participants described these challenges as occurring due to their own experiences of counselor development, as well as working specifically with at-risk populations within certain institutional barriers. The challenges described fit within three subthemes: (a) counselor-in-training challenges, (b) institutional challenges, and (c) client challenges. These subthemes and supporting quotes are described in the following sections.

\section{Counselor-in-training challenges}

Participants described experiencing challenges due to being novice counselors working with clients for the first time. The participants described lessons learned from their work with at-risk populations. One participant stated:

"I think that was something that was challenging for me in the beginning, was kind of letting the client go where they wanted to go. And it's really about their success. It's not really my idea of what their success looks like, so that was definitely something I learned."

Another participant reported the challenge of awareness and recognition that the participant's reality was not necessarily the reality of the client; therefore, the participant was tasked with intentionally "[b]eing aware of my surroundings, their surroundings, and how they view the world." Moreover, a participant described working with parents who doubted their competence due to their age: "But I just try to empower them and make sure they knew that they're the experts of their own lives ... teach me about your experiences ... so I just tried to validate where they were."

\section{Institutional challenges}

Participants also noted the institutional barriers to providing counseling services to at-risk children and families within their training organizations. One participant described the lack of resources for the families in their training agency:

I'm at a very high-risk, low SES [socioeconomic status], rural school ... and it's three hundred ninety-five kids and eighty percent free lunch. Parent night and things like that 
don't ever happen, because there is no transportation. The numbers don't match the risk, so there's not really enough support for the level of risk within the school.

Other participants reported that the institutions they trained in did not view the clients from an ecological perspective, which seemed to truly hinder meeting the needs of the at-risk populations they served. A participant reported, "They don't look at it from the holistic point of view that these kids have serious issues going on in their personal lives, environment at home, family stuff." Similarly, another participant mentioned:

One kid of mine was flunking pretty much everything. Like he had a really bad attitude. But it turns out his brother was sent to prison recently. So he's dealing with that, and that is why he's not doing well in school. He can't focus at all. So it's just kind of finding out more from their kids. They just say, "Yeah, get him tutoring - that'll fix it." And it's like no, it may help, but not all (of it).

The participants also stated that there was difficulty getting buy-in to alter the services to the clients to better meet their needs, and that school personnel had different ideas of the role of the counselor or counselor in training. One participant said, "I don't think they really understood my role in the school. I think they thought I was overstepping what they were supposed to do."

\section{Client challenges}

Participants described the challenges of working with at-risk children, youth, and their families. The students described barriers to the change process in counseling that occurred because of clients being mandated to come or youth being required to receive services due to discipline referrals. One participant reported, "I've actually had a student say that he doesn't care if he gets in trouble ... and he just sort of resigned himself to 'This is what is going to happen and there is nothing I can do about it." Another participant described working with mandated families:

Working with mandated clients was kind of hard for me. A lot of the families that we had were kind of required to come ... so there was a lot of pushback a lot of times.

Sometimes families didn't really understand the process of therapy because lot of them have never experienced that ... a lot of them didn't want to work. But the ones that did, it was really rewarding.

Along with the challenges of the at-risk populations being mandated to receive services, the students described the importance of being aware of the underlying reasons the clients may have presented for services and looking beyond the initial referral to truly help resolve clients' needs. One participant stated, "It would quickly come to the forefront that it was actually a much deeper issue ... and that was the only way to get rid of that was to actually address it."

\section{Theme 3: Support}

When reflecting on the experience, support for the participants was a reoccurring theme. Participants identified both receiving support and facing challenges around navigating different departments, administration, and other disciplines. Overall, participants described the 
supervision within the experience as being a vital role of their professional development, navigating dynamics, and supporting their introduction into working with clients. The participants identified two subthemes of support that were presented during their experiences: personal and professional.

\section{Personal}

Personal support was presented through mentorship and promoting the student's wellness from supervisors or administrators:

"I was lucky to have a supervisor who really promotes self-care. You know, she encouraged me a lot of times, like, 'When you leave here, leave everything you did here. Don't take it home with you.'”

This participant added that her supervisor noticed that she was taking the work home with her emotionally. The participant described ruminating over the clients nightly. The participant noted that having the supervisor there for support during the workday was helpful in unloading and verbalizing the impact that clients were having on her. Other participants describe personal support as having an individual who had their back, supported their experiences, and made way for them to take ownership of their internships.

\section{Professional}

Most participants identified at least one individual within the school system that supported their goals and development. Professional support was described through the supervisory relationship during both individual and group supervision but also outside of supervisory relationship. Participants described learning about how to collaborate with professionals outside of the school system and that direct feedback from supervisors during live supervision was most helpful. In addition, the participants described collaboration between departments and professionals for support, such as working with administrators, teachers, and gaining additional training. One participant described the support felt through her development as a counselor and the increased confidence in utilizing various interventions: "I felt like I was really supported throughout all those different levels, whereas now I can put an intervention into place effectively."

Although participants were able to identify positive experiences of support, they also described ways that they were not supported, which led to a greater awareness of their professional development needs and future employment considerations. One participant did not feel supported by the guidance department and consistently had to seek support from administrators, which was discouraging and led to confrontation. Another participant described that the lack of support from administration for the counseling department within the school led the participant to decline a job offer from the school upon graduation. Other participants described having difficulty obtaining buy-in from teachers and other staff members to implement projects or work with students, which led to barriers and challenges in navigating the overall experience.

Theme 4: Counselor Development 
Although counselor development is an ongoing process and the main focus of counseling training in general, the participants highlighted conscious awareness of their development both professionally and personally through their experiences working with at-risk adolescents in an alternative school setting. One participant described this growth experience:

I think it's definitely just similar to the program, how you go through this parallel process of like becoming a counselor, and you're doing all of this like self-growth as a part of the program, and that's just continued in my placement. I feel like the person that I was as a counselor when I walked in on the first day is drastically different from the counselor that I am now. And that felt really empowering.

\section{Professional competence}

For some participants, their professional competence appeared to strengthen through their enhanced understanding and use of research in the counseling environment as well as presenting their work at a professional conference. One participant, in describing her growth from before to after using action research, stated:

It's kind of given, I think, all of us knowledge of how to do an action grant research project. I mean, if you had asked me to do this before now, I would have said, "What? How do I do that? What needs to happen? What does it look like? How do I get the data? How do I put it on a huge poster board? And how do I kind of promote it?" And things like that. And so now I feel that going forward, it's something I could do again looking at something different. And that's really neat.

Another participant expressed excitement at using research and evaluations to assist in positive client outcomes as well as creating something tangible to illustrate client improvement and proof of treatment effectiveness. This participant stated,

You're not just kind of hanging out or talking to kids, which is helpful, but this gives you something tangible and you can say, "Here is this binder with this career group I've been doing for five years, and here are my results for five years. And here's how we've changed it." And you can implement that for a multitude of different subjects.

\section{Personal self-efficacy}

Although engaging in action research with at-risk populations created some skepticism among participants, it appeared to be helpful in improving personal self-efficacy for some. One participant stated, "I'm not a big research person myself; it's just not my favorite thing in the world. But it was nice to go back and see what I implemented throughout the process, and be like, 'Wow, I did do that, I did that too." Similarly, other participants reported, "It also made me feel like, okay, like my people are reducing their score on this assessment, so what I'm doing must be helping" and "It was a nice reflection on what I did with my clients and to realize that I did have an impact, so it was nice to see the results." While some participants focused on the action research component of this experience, other participants reported a significant impact of 
the entire experience overall on their personal growth and development. As one participant stated:

I think, like, this whole entire process I've learned more about myself. Like as far as the population I want to work with, I already, like, knew what population I want to work with. This just kind of solidified it a little bit more for me. I think it was the personal growth that impacted me the most.

\section{Questionnaire}

We included the results of the evaluation questionnaire in Table 1. Participants' responses to the evaluation prompts reflect highly favorable perceptions of their training experiences. Participants self-reported an increase in confidence in counseling at-risk populations and evaluating evidence-based practice interventions through action research.

\section{DISCUSSION AND IMPLICATIONS}

Based on the experiences shared during focus groups and evaluative data obtained through participant questionnaires, interdisciplinary collaboration was a key theme that emerged as valuable to the counselor trainees during their experiences working with at-risk populations. Participants described their experiences with interdisciplinary collaboration as beneficial for their learning, as well as their ability to provide accessible resources and services to their clients, which, according to Cox et al. (2014), is consistent with Affordable Care Act standards. In addition, all participants indicated on the evaluation questionnaire that they were more confident in their ability to engage in interdisciplinary collaboration following their training experiences and requirement to do so in their internship settings. Previous studies providing educational interventions to counselors in training in school settings have also showed promise in promoting future counselors' competency engaging in interdisciplinary collaboration (Iachini et al., 2015; Splett et al., 2010). Participants also reported that, when engaging in interdisciplinary collaboration, there were barriers and challenges to enhancing client outcomes within their organizations and with providers from external social service agencies. Therefore, it may be advantageous for counselor education programs to consider implementing curriculum related to interdisciplinary collaboration among counselors and other helping professionals who work with at-risk youth, as well as how to overcome challenges they may experience. For example, programs could collaborate with other disciplines on campus (e.g., school psychology, social work, nursing, medicine) to design collaborative consultation courses where students discuss cases from interdisciplinary perspectives. In addition, counselor education programs could focus on building strong, collaborative relationships with internship sites to enhance counselor-intraining internship/practicum experiences and reduce barriers.

Participants described additional barriers in their experiences, which were related to their lack of counseling experience, institutional barriers hindering their work with at-risk populations, and challenges that arose when working with at-risk populations. Participants' experiences were consistent with previous research findings regarding the needs of at-risk populations. Students described a lack of resources within their settings to meet the substantial needs of at-risk populations due to poverty and stressful home environments (Stegman \& Cooper, 2010). Many 
participants reported that other professionals in their internship organizations appeared to lack a holistic understanding about how the at-risk youth's environment impacted their presenting emotional and behavioral concerns. Professionals in the field sometimes lack knowledge about the impacts of high-stress home environments on at-risk youth's ability to function well in social and school settings (Essex et al., 2006). Thus, more training programs, such as the one described in this article, are needed to prepare professionals in a variety of disciplines to best meet the needs of at-risk populations and improve their overall functioning. This information could be incorporated throughout coursework, throughout professional development opportunities for students and community practitioners provided by program faculty, and by encouraging students to attend conferences focused on this topic. Program faculty could also encourage their students groups (e.g., Chi Sigma Iota) to engage in advocacy projects for at-risk populations. Some areas for future research include more training for teachers and school administrators in understanding at-risk students' social and emotional needs. In addition, teacher and school administrator training on identification of behaviors connected to mental health concerns can assist with school personnel viewing students more holistically and can provide teachers with the tools and resources to respond empathically versus emotionally. Finally, future research can focus on the effectiveness of counselor training programs in teaching and practicing interdisciplinary collaboration.

At-risk youth need greater access to evidence-based treatments for their mental health concerns (Burns et al., 1995; Merikangas et al., 2010). The training program evaluated in this article sought to increase participants' ability to provide evidence-based practices to at-risk populations. As mentioned, Table 2 provides further information about some of the evidence-based practices the student participants implemented with at-risk populations in action research projects during the training program. Given the results of the evaluation survey and focus-group responses, participants felt more confident in their ability to counsel at-risk populations, provide effective interventions, and evaluate their practice. Participants believed they could implement action research and interventions learned during their training in their future professional career. Counselor education students could benefit from opportunities to receive training in evidencebased practices for working with at-risk youth. Moreover, it could be advantageous for counselor education students to engage in evaluation of practice through action research while providing service to at-risk populations during their coursework and practicum/internship experiences. It is possible that these experiences could carry over into students' professional counseling careers postgraduation, which could increase evidence-based counseling services to underserved populations.

Finally, participants valued support during their training experience working with at-risk youth, specifically from supervisors and colleagues in their internship settings. Due to the high needs of the populations with whom they were working (Burns et al., 1995; Hogan, 2003; Merikangas et al., 2010), students found it vital to have supportive supervisors and colleagues to help them navigate challenges they faced providing services in their internship settings. Participants described various reactions to learning about at-risk youth's experiences. Many of the participants endorsed the importance of being able to process personal responses to working with at-risk youths with a supervisor or colleague. Counselor education programs could benefit from providing training to on-site supervisors in internship settings to help improve student support and wellness in organizations serving at-risk youth. Overall, participants appeared to have a 
positive learning experience. In fact, all students indicated on the questionnaire that they plan to work with at-risk populations in the future.

\section{LIMITATIONS}

Generalizability of the findings is not possible given the evaluative nature of the survey and qualitative methodology utilized in the study. Given the descriptive data provided from the evaluation survey, no causal inferences can be made about the effect of the training experience on the students' development and knowledge. The grant funding received to implement the training program made many of the opportunities the students received possible. It may be difficult to fully replicate the training program in settings where this funding is not available. Given that the purpose of the study is to evaluate the specific grant-funded training program, the limitations provided were anticipated.

\section{CONCLUSION}

Many at-risk children, adolescents, and transitional-age youth are underserved related to their mental health concerns. Given the identified needs, we provided the training opportunity outlined in this article with the support of a federal grant to increase evidence-based services to at-risk populations. The article outlined the findings of a qualitative evaluation inquiry into a training program provided to counselor trainees in an effort to increase knowledge for counselor education programs about how to implement similar interventions with their students.

\section{DISCLOSURE STATEMENT}

No potential conflicts of interest were reported by the authors.

\section{FUNDING}

This work was supported by the U.S. Health Resources and Services Administration (G02HP30562).

\section{REFERENCES}

American School Counselor Association. (2016). ASCA ethical standards for school counselors. Alexandria, VA: Author. Retrieved from https://www.schoolcounselor.org/asca/media/asca/Ethics/EthicalStandards2016.pdf

Braun, V., \& Clarke, V. (2006). Using thematic analysis in psychology. Qualitative Research in Psychology, 3, 77-101. doi:10.1191/1478088706qp063oa

Brott, P. E. (2006). Counselor education accountability: Training the effective professional school counselor. Professional School Counseling, 10(2), 179-187. doi:10.5330/prsc.10.2.d61g0v3738863652

Burns, B., Costello, E. J., Angold, A., Tweed, D., Stangl, D., Farmer, E. M. Z., \& Erkanli, A. (1995). Children's mental health service use across service sectors. Health Affairs, 14(3), $147-158$. 
Clarke, V., \& Braun, V. (2016). Thematic analysis. The Journal of Positive Psychology, 12(3), 297-298. doi:10.108/17439760.2016.1262613

Cleveland, M. J., Feinberg, M. E., Bontempo, D. E., \& Greenberg, M. T. (2008). The role of risk and protective factors in substance use across adolescence. Journal of Adolescent Health, 43(2), 157-164. doi:10.1016/j.jadonhealth.2008.01.015

Cox, J., Adams, E., \& Loughran, M. J. (2014). Behavioral health training is good medicine for counseling trainees: Two curricular experiences in interprofessional collaboration. Journal of Mental Health Counseling, 36(2), 115-129. doi:10.17744/mehc.36.2.c426q74431666762

Deighton, J., Humphrey, N., Belsky, J., Boehnke, J., Vostanis, P., \& Patalay, P. (2018). Longitudinal pathways between mental health difficulties and academic performance during middle childhood and early adolescence. British Journal of Developmental Psychology, 36(1), 110-126. doi:10.1111/bjdp.12218

Dupéré, V., Dion, E., Leventhal, T., Archambault, I., Crosnoe, R., \& Janosz, M. (2018). High school dropout in proximal context: The triggering role of stressful life events. Child Development, 89(2), 107-122. doi:10.1111/cdev.12792

Ellickson, P. L., Orlando, M., Tucker, J. S., \& Klein, D. J. (2004). From adolescents to youth adulthood: Racial/ethnic disparities in smoking. American Journal of Public Health, 94(2), 293-299. doi:10.2105/AJPH.94.2.293

Essex, M. J., Kraemer, H. C., Armstrong, J. M., Boyce, W. T., Goldsmith, H. H., Klein, M. H., \& Kupfer, D. J. (2006). Exploring risk factors for emergence of children's mental health problems. Archives of General Psychiatry, 63(11), 1246-1256. doi:10.1001/archpsyc.63.11.1246

Hadiwijaya, H., Klimstra, T. A., Vermunt, J. K., Branje, S. J. T., \& Meeus, W. H. J. (2017). On the development of harmony, turbulence, and independence in parent-adolescent relationships: A five-wave longitudinal study. Journal of Youth and Adolscence, 46(8), 1772-1788. doi:10.1037/t06336-000

Hogan, M. F. (2003). The president's new freedom commission: Recommendations to transform mental health care in America. Psychiatric Services, 54(11), 1467-1474. doi:10.1176/appi.ps.54.11.1467

Iachini, A. L., Warren, M. E., Splett, J. W., George, M. W., Taylor, L. K., \& Weist, M. D. (2015). Exploring the impact of a pre-service interprofessional educational intervention for school mental health trainees. Journal of Interprofessional Care, 29(2), 162-164. doi:10.3109/13561820.2014.934957

Interprofessional Education Collaborative Expert Panel. (2011). Core competencies for interprofessional collaborative practice: Report of an expert panel. Washington, DC: Interprofessional Education Collaborative.

Larson, S., Chapman, S., Spetz, J., \& Brindis, C. D. (2017). Chronic childhood trauma, mental health, academic achievement, and school-based health center mental health services. Journal of School Health, 87(9), 675-686. doi:10.1111/josh.12541 
Lincoln, Y. S., \& Guba, E. G. (1986). But is it rigorous? Trustworthiness and authenticity in naturalistic evaluation. New Directions For Program Evaluation, (30), 73-84.

doi:10.1002/ev.1427

McLeod, J. D., \& Fettes, D. L. (2007). Trajectories of failure: The education careers of children with mental health problems. American Journal of Sociology, 113, 653-661. doi:10.1086/521849

McLeod, J. D., \& Kaiser, K. (2004). The relevance of childhood emotional and behavioral problems for subsequent educational attainment. American Sociological Review, 69(5), 636-658. doi:10.1177/000312240406900502

Merikangas, K. R., He, J., Burstein, M., Swanson, S. A., Avenevoli, S., Cui, L., \& Swendsen, J. (2010). Lifetime prevalence of mental disorders in U.S. adolescents: Results from the national comorbidity survey replication-adolescent supplement (NCS-A). Journal of the American Academy of Child and Adolescent Psychiatry, 49(10), 980-989. doi:10.1016/j.jaac.2010.05.017

Needham, B. L., Crosnoe, R., \& Muller, C. (2004). Academic failure in secondary school: The inter-related role of health problems and educational context. Social Problems, 51, 569586.

Patient Protection \& Affordable Care Act. (2010). 42 USC $\S 18001$ et seq.

Sessa, F. M. (2005). The influence of perceived parenting on substance use during the transition to college: A comparison of male residential and commuter students. Journal of College Student Development, 46(1), 62-74. doi:10.1353/csd.2005.0010

Splett, J. W., Coleman, S., Maras, M. A., Gibson, J. E., \& Ball, A. (2010). Learning by teaching: Reflections on developing a curriculum for school mental health collaboration. Advances in School Mental Health Promotion, 4, 27-38. doi:10.1080/1754730X.2011.9715627

Stegman, S., \& Cooper, J. L. (2010). Children's mental health: What every policymaker should know. New York, NY: National Center for Children in Poverty, Columbia University.

Stewart, D. W., \& Shamdasani, P. N. (1990). Focus groups: Theory and practice. Newbury Park, CA: Sage.

Tang, Z., \& Orwin, R. G. (2009). Marijuana initiation among American youth and its risks as dynamic processes: Prospective findings from a national longitudinal study. Substance Use \& Miuse, 44(2), 195-211. doi:10.1080/10826080802347636

Vitaro, F., Brendgen, M., Larose, S., \& Tremblay, R. E. (2005). Kindergarten disruptive behaviors, protective factors, and educational achievement by early adulthood. Journal of Educational Psychology, 97, 617-629. doi:10.1037/0022-0663.97.4.617

Wechsler, H., \& Nelson, T. F. (2008). What we have learned from the Harvard school of public health college alcohol study: Focusing attention on college student alcohol consumption and the environmental conditions that promote it. Journal of Studies N Alcohol and Drugs, 69(4), 481-490. doi:10.15288/jsad.2008.69.481 